\title{
Smart Textile Integrated Wireless Powered Near Field Communication (NFC) Body Temperature and Sweat Sensing System
}

DOI:

10.1109/JERM.2019.2929676

\section{Document Version}

Accepted author manuscript

Link to publication record in Manchester Research Explorer

Citation for published version (APA):

Jiang, Y., Pan, K., Leng, T., \& Hu, Z. (2019). Smart Textile Integrated Wireless Powered Near Field Communication (NFC) Body Temperature and Sweat Sensing System. IEEE Journal of Electromagnetics, RF and Microwaves in Medicine and Biology, 1-1. https://doi.org/10.1109/JERM.2019.2929676

\section{Published in:}

IEEE Journal of Electromagnetics, RF and Microwaves in Medicine and Biology

\section{Citing this paper}

Please note that where the full-text provided on Manchester Research Explorer is the Author Accepted Manuscript or Proof version this may differ from the final Published version. If citing, it is advised that you check and use the publisher's definitive version.

\section{General rights}

Copyright and moral rights for the publications made accessible in the Research Explorer are retained by the authors and/or other copyright owners and it is a condition of accessing publications that users recognise and abide by the legal requirements associated with these rights.

\section{Takedown policy}

If you believe that this document breaches copyright please refer to the University of Manchester's Takedown Procedures [http://man.ac.uk/04Y6Bo] or contact uml.scholarlycommunications@manchester.ac.uk providing relevant details, so we can investigate your claim.

\section{OPEN ACCESS}




\title{
Smart Textile Integrated Wireless Powered Near Field Communication (NFC) Body Temperature and Sweat Sensing System
}

\author{
Yutong Jiang, Kewen Pan, Ting Leng and Zhirun Hu, Member, IEEE
}

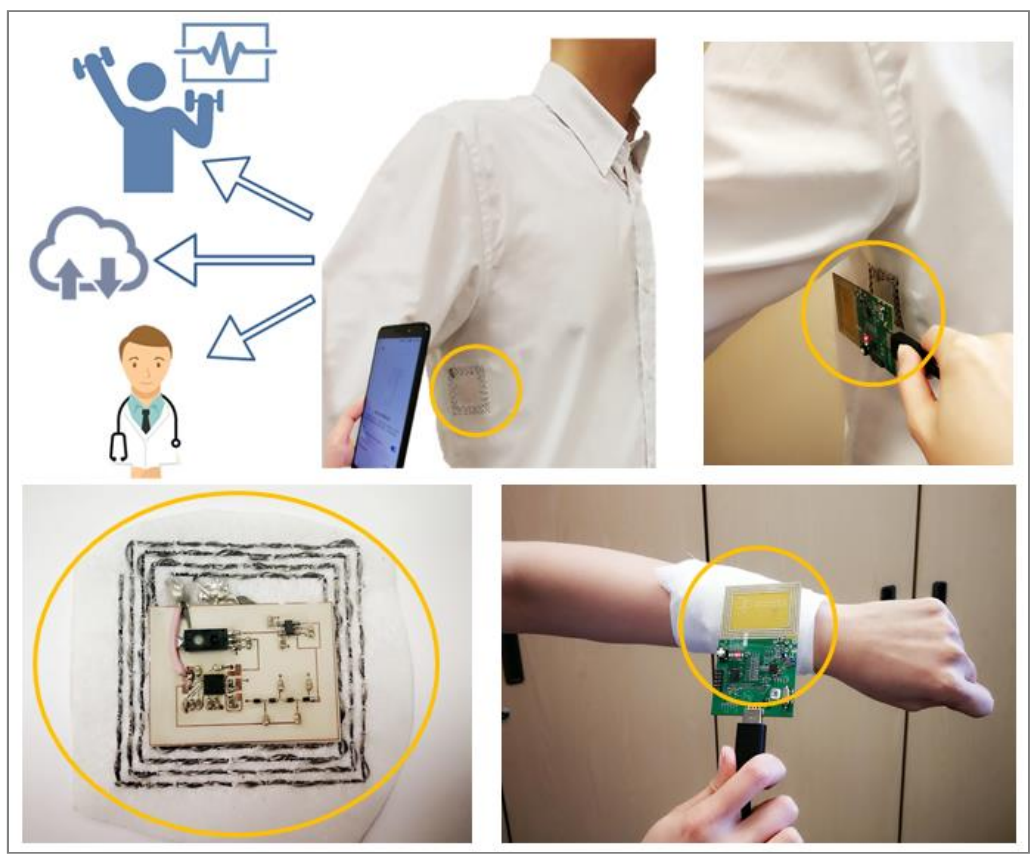

A battery free wearable sensing device with temperature and sweat sensors embedded into and powered by a smart textile NFC antenna available for both NFC readers and NFC enabled smart phones, which can take part in various medical applications such as daily healthcare, fever detection and wound healing monitoring.

\section{Take-Home Messages}

- In this manuscript, body temperature and sweat sensors are integrated with a textile NFC antenna, which eliminates the need for external batteries and realizes real-time wireless monitoring.

- This paper has presented design, fabrication implementation, measurements and real-life applications of smart textile NFC antennas and a battery-free wireless NFC body temperature and sweat sensing device, aiming for truly ubiquitous wireless health and wellbeing monitoring.

- The proposed device targets at body temperature and sweat loss monitoring for daily healthcare, systemic hyperthermia from fever, sweating symptoms caused by various kinds of infection, inflammation and trauma and wound healing monitoring.

- Different from conventional battery enabled and wire connected sensors, the significance of this work is by applying textile NFC as a communication interface as well as a wireless power harvester, battery-free realtime body temperature and sweat monitoring has been realized simultaneously.

- Apart from the device itself, an App has also been developed on Android system for the sensor data to be accessed by smart phones. 


\title{
Smart Textile Integrated Wireless Powered Near Field Communication (NFC) Body Temperature and Sweat Sensing System
}

\author{
Yutong Jiang, Kewen Pan, Ting Leng and Zhirun Hu, Member, IEEE
}

\begin{abstract}
Near Field Communication (NFC) is a short-range wireless communication technique that has become attractive devices for healthcare and wellbeing monitoring. The work reported here demonstrates the development of a battery free wearable sensing system with temperature and sweat sensors embedded into and powered by a smart textile NFC antenna. The NFC antenna is seamlessly integrated with closed-body garments, and sensor data can be easily acquired by NFC readers and smart phones in order to achieve real time and wireless monitor of health status in a convenient and non-intrusive way. A Dickson charge pump circuit has been designed and implemented in order to pump up the voltage and ensure a steady voltage supply for the sweat sensor. The maximum read range for accessing sensor data is $6 \mathrm{~cm}$. The on-body measurement accuracy of the temperature sensor and sweat sensor are able to achieve $\pm 0.14^{\circ} \mathrm{C}$ and $\pm 0.2 \%$, respectively. The presented system can provide wearable battery-free ubiquitous wireless connectivity for point-of-care and any time healthcare and wellbeing monitoring.
\end{abstract}

Keywords - Near Field Communication (NFC), temperature sensor, sweat sensor, e-textile, integrated sensing systems, low power electronics, IoT.

\section{INTRODUCTION ${ }^{1}$}

$\mathrm{I}_{\mathrm{i}}^{\mathrm{N}}$ recent years, great interest has been raised in integrating electronic devices, such as antennas, electrodes and sensors with daily wearables to form etextiles[1], [2]. Since clothes are the most elemental and necessary wearables in our daily life, e-textile sensing devices for personal health care have taken part in various medical applications and internet of things (IoT) [3], [4]. The significance of close-body sensors is also highlighted in their contribution to preventive healthcare by constantly raising the uses' awareness of their health status [5].

The main advantage of e-textile integrated sensors is that they are easy and comfortable to wear while providing a convenient and spontaneous way for real-time monitoring one's health status without affecting one's daily life [6], [7]. Among current researches of textile based sensors for health care, most applications have been limited to textile properties, such as pressure sensors for posture monitoring [8]-[10], stretching sensors for ionic species loss [11], bending sensors for heartbeat and respiration [12], and wetness sensors for salinized liquids [13]. In [14] and [15], body temperature and humidity sensors fabricated with conductive textile have been reported. However, all of these sensors are powered by batteries, and the sensing data are acquired through wires and analyzed with data centers such as PCs. The extra work in sensor charging and data

Manuscript received $20^{\text {th }}$ March, 2019. This work is supported in part by UK Engineering and Physical Research Council, EU Graphene Flagship Program under Grant EPN010345. (Corresponding author: Zhirun $\mathrm{Hu}$ )

Y. Jiang, K. Pan. T. Leng and Z. Hu are with the EEE Department, University of Manchester, UK. (e-mail: yutong.jiang@manchester.ac.uk; kewen.pan@manchester.ac.uk; $\quad$ ting.leng@manchester.ac.uk; z.hu@manchester.ac.uk) processing makes it less desirable in daily personalized healthcare. In this work, e-textile NFC antennas have been developed to be integrated with external temperature and humidity sensors in order to enable battery-free wireless sensing. NFC antennas can be considered as small energy harvesting devices that contribute to green electronic technology since they only rely on the RF power emissions from the reader [16]. Over the past decade, NFC has become one of the potential solutions in wireless health and wellbeing monitoring applications for its low cost, low power consumption, easy access and ability of integration with multiple types of smart sensors [17], [18]. In [19], interfacing external sensors (temperature, humidity, light, pressure etc.) with smart phones through NFC was proposed. In wearable developments, NFC enabled skinmounted sensing device for heart rate and blood flow has been presented in [20]. However, the development of integrating body-worn textile NFC embedded with sensors for real-time healthcare and wellbeing monitoring has yet to be reported. Based on the characteristics and performance of e-textile NFC antennas discussed in [21] and [22], the contribution and novelty in this work are by applying textile NFC as a communication interface as well as a wireless power harvester, battery-free real-time body temperature and sweat monitoring has been realized simultaneously.

In this paper, we propose a battery-free smart textile NFC enabled sensing device for body temperature and sweat loss monitoring. The NFC antenna is fabricated with silver coated conductive threads and cotton substrate, which is enabled by an NFC sensor transponder (RF430FRL152H, Texas Instruments) connected to an external humidity sensor. In order to achieve battery-free operation, a voltageboosting rectifier has been applied to provide the DC power required by the humidity sensor wirelessly. An App has also been developed on Android system for the sensor data 
to be accessed by smart phones. This development aims for real-time monitoring personal body temperature and sweat loss associated with systemic hyperthermia from fever and sweating symptoms which are often caused by various kinds of infection, inflammation and trauma [23]. It can also be applied in monitoring wound healing progress, daily healthcare and wellbeing.

The main challenge faced by the proposed design is that the conformal structure of textile can easily affect sensor performance under body movements such as bending and stretching. As a solution, the material influence is reduced by minimizing the circuit size and selecting a relatively less influential body location to place the device.

This paper is structured as follows. Section II will demonstrate the overall structure of the textile sensing circuit as well as the design, fabrication and testing of each constituent part of the system including textile NFC circuits, voltage boosting rectifiers and sensors. In Section III, the experiments and measurement results of temperature and humidity sensors are presented. In Section IV, potential applications of this device both for daily use and medical employment are proposed. Section V summarizes the key results and overall circuit performance.

\section{ON BODY CIRCUIT DESIGN}

\section{A. Sensing System Architecture}

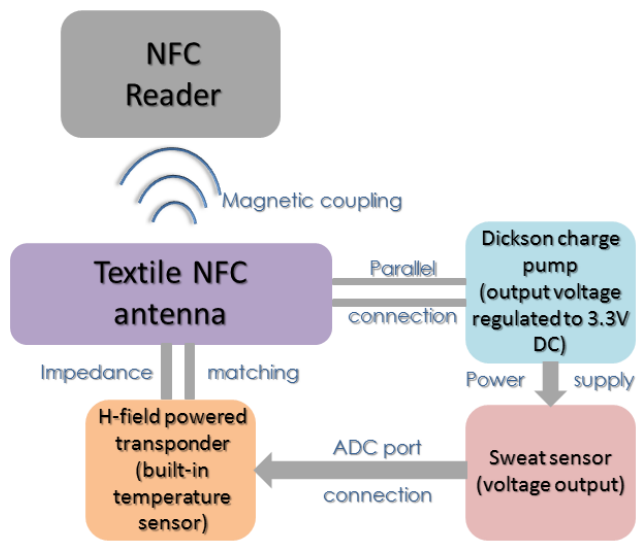

Fig. 1. The sensing system architecture.

The sensing system architecture shown in Fig. 1 presents the overall operation methodology of the proposed textile sensing device. A transponder microchip with a build-in temperature sensor is connected to the textile NFC antenna with conjugate impedance matching for maximum power efficiency. When an NFC reader detects the antenna within a read range, the antenna wirelessly receives power to supply the sensor transponder. The maximum output power of the reader (TRF7970A, Texas Instruments) is $23 \mathrm{dBm}$ $(200 \mathrm{~mW})$, and the operating power of the transponder (RF430FRL152H, Texas Instruments) at $13.56 \mathrm{MHz}$ and the sweat sensor (HIH-5031, Honeywell) are around $2.85 \mathrm{~mW}$ and $600 \mathrm{uW}$, respectively.

Since almost all commercial humidity sensors operate with external DC voltage source, a Dickson charge pump and a voltage regulator is developed as a voltage boosting rectifier connected between the NFC antenna and the sweat sensor. Meanwhile, the output voltage of the sweat sensor is connected to an ADC input pin of the NFC transponder so that the reader is able to collect data from both sensors (temperature and sweat) simultaneously.

\section{B. Smart Textile NFC Antennas}

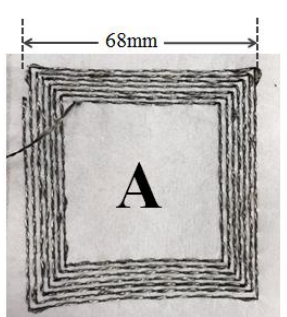

(a)

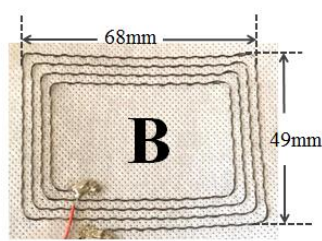

(b)

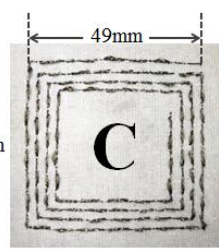

(c)
Fig. 2. Textile NFC prototypes with inductance of (a) $5.86 \mu \mathrm{H}$ (Antenna A), (b) $1.84 \mu \mathrm{H}$ (Antenna B) and (c) $1.42 \mu \mathrm{H}$ (Antenna C)

Smart textile NFC antennas are NFC antennas fabricated by integrating conductive threads with nonconductive textile substrate, which are enabled by conjugate matching with capacitive microchips.

In [21], we have presented the fabrication process and choices of conductive threads, substrate material and embroidery technique of textile NFC antennas. To further investigate the antenna properties and select the best antenna structure for the sensing device, three textile NFC prototypes of different sizes and inductances presented in Fig. 2 are studied. The prototypes are fabricated with cotton substrate and silver coated nylon threads (Arduino Flux Workshop) with resistance of $17.2 \Omega / \mathrm{m}$.

The inductance, resistance at $13.56 \mathrm{MHz}$ and $\mathrm{Q}$ factors for the NFC antennas are listed in Table I, where the quality factors of NFC antennas are calculated using (1). As the relative difference between antenna inductances is much greater than resistances, antenna A possesses the best transmission efficiency due to its large inductance and receiving surface for magnetic flux. In reality, however, the relatively large sized and densely packed conductive threads might make it less practical.

$$
Q=\frac{2 \pi f_{r} L_{a n t}}{R_{e q}}
$$

where $L_{\text {ant }}$ represents the antenna inductance, $f_{r}$ represents the operating frequency $(13.56 \mathrm{MHz})$ and $R_{e q}$ represents the antenna resistance at $13.56 \mathrm{MHz}$.

\section{TABLE I: NFC ANTENNA PARAMETERS}

\begin{tabular}{|c|c|c|c|}
\hline $\begin{array}{c}\mathbf{N F C} \\
\text { antenna }\end{array}$ & $\mathrm{A}$ & $\mathrm{B}$ & $\mathrm{C}$ \\
\hline $\mathbf{L}_{\text {ant }} / \boldsymbol{\mu H}$ & 5.86 & 1.84 & 1.42 \\
\hline $\mathbf{R}_{\mathbf{e q}} / \mathbf{\Omega}$ & 24.8 & 15.9 & 13.5 \\
\hline $\mathbf{Q}$ factor & 20.13 & 9.86 & 8.96 \\
\hline
\end{tabular}

Since the textile based circuits are so flexible that they can be easily bent from body movements of the user, the bending test demonstrated in [21] has been applied to observe how the electrical properties of the antenna $A$ and $\mathrm{C}$ (antennas with highest and lowest $\mathrm{Q}$ factors) respond to 
bending. The measurements are taken using Keysight Fieldfox VNA N9918A, and the test results are presented in Fig. 3. Fig. 3(a) shows how the inductances of the two antennas vary with increasing bending angles. As each antenna is gradually bent from $0^{\circ}$ to $180^{\circ}$ with its midcourt line being the axis, the inductance of antenna $\mathrm{A}$ and $\mathrm{C}$ drops from $5.86 \mu \mathrm{H}$ to $4.73 \mu \mathrm{H}$ and from $1.42 \mu \mathrm{H}$ to $1.04 \mu \mathrm{H}$, respectively. The decrement is particularly rapid at the bend range between $120^{\circ}$ and $180^{\circ}$.

$$
f_{r}=\frac{1}{2 \pi \sqrt{C_{\text {chip }{ }^{L} \text { ant }}}}
$$

where $C_{\text {chip }}$ stands for the transponder capacitance, $L_{a n t}$ for the antenna inductance and $f_{r}$ the resonant frequency.

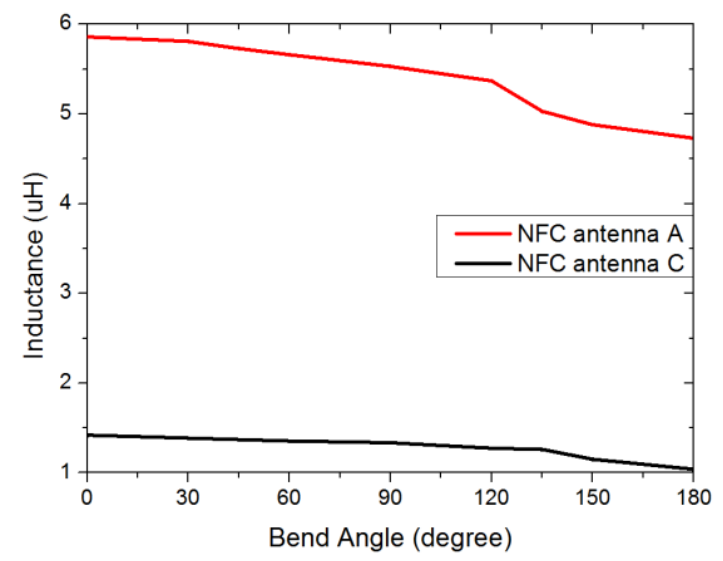

(a)

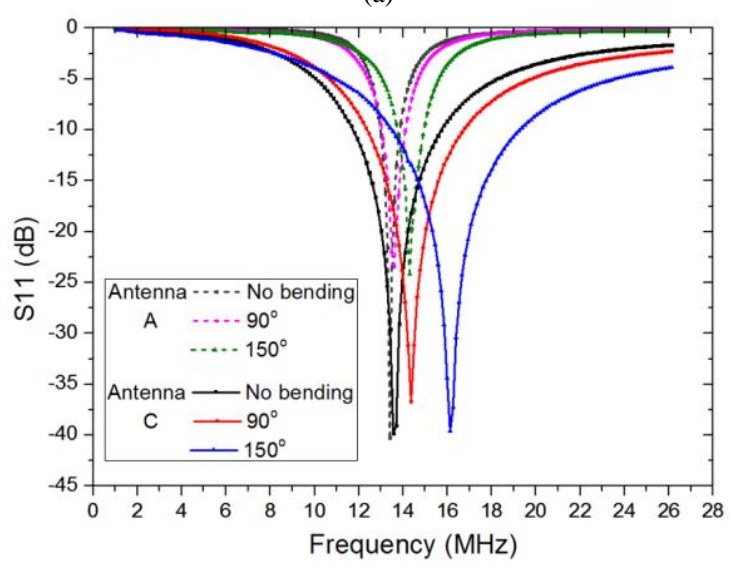

(b)

Fig. 3. (a) Inductance variation of NFC antennas at $13.56 \mathrm{MHz}$ with bend angle and (b) Measured magnitudes of $S_{11}$ of Antennas $A$ and $C$ in Fig. 2, where the textile antennas are bent with angles: $90^{\circ}$ and $150^{\circ}$.

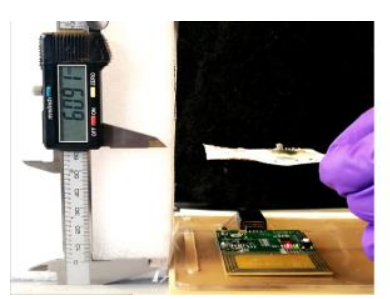

(a)

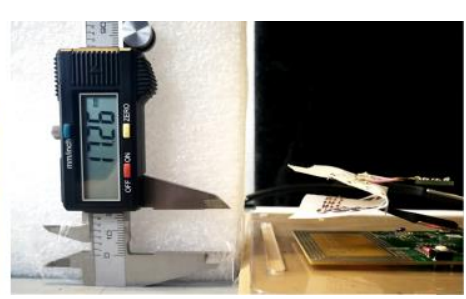

(b)
Fig. 4. (a) NFC tag read range measurement set up (b) NFC tag reading with 150 degree bend angle.

It can be deduced from (2) that decreasing antenna inductance would lead to small increments in the antenna resonant frequency. In Fig. 3(b), where the $S_{11}$ (magnitude) of antenna $\mathrm{A}$ and $\mathrm{C}$ are measured with increasing bending angles, the measured operating frequency of the antennas indeed increases with the degree of bending. Corresponding to the trend in Fig. 3(a), the central frequency shift between the bend angles of $90^{\circ}$ and $150^{\circ}$ appears as the greatest. Since antenna A possesses a much narrower bandwidth, the $10 \mathrm{~dB}$ frequency band of antenna A shifts further away from $13.56 \mathrm{MHz}$ than antenna $\mathrm{C}$ under bending, which means it would take more influence in wireless reading performance. Therefore, considering a wearable sensing circuit comes under inevitable bending caused by natural body movements, antenna $\mathrm{C}$ has been selected as the NFC interface for its stable performance and relatively small size that is more desirable for on-body placement.

As presented in Fig. 4(a), an NFC transponder (RF430FRL152H, Texas Instruments) is connected to antenna C. The read range measured with a TRF7970A (Texas Instruments) reader is $6.09 \mathrm{~cm}$. As it shows in Fig. 4(b), the tag is able to be detected under a maximum bent angle of $150^{\circ}$, where the angle is maintained using scotch tape and plastic tweezers. The read distance under this condition is $1.73 \mathrm{~cm}$.

\section{Voltage Boosting Rectifiers}

In this work the selected humidity sensor (HIH-5031, Honeywell) (used as sweat sensor) operates at DC voltage of $3 \mathrm{~V}$ and input current of $200 \mu \mathrm{A}$. The main challenge for an NFC tag to perform as a wireless power supply for external sensors lies in the low AC voltage it provides. To overcome this, a voltage multiplier is developed within the circuit in order to raise the supply voltage level for the sensors as well as smooth up the current [24].

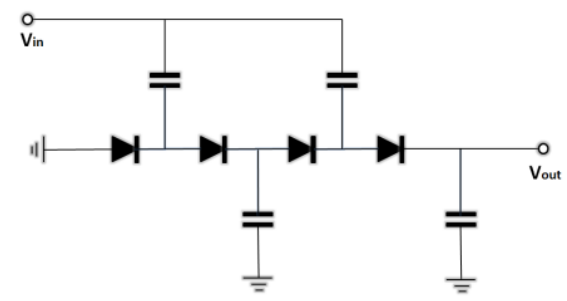

Fig. 5. Dickson charge pump circuit layout.

Fig. 5 presents a modified structure of a Dickson charge pump, which can be regarded as a half-wave N-stage voltage multiplier [25]. The circuit operates by gaining packets of charge from coupling capacitors charged and discharged at two anti-phased clock cycles, and pushing them along the diode chain [26]. Since each coupling capacitor is approximately charged to the input drive voltage, ideally, the charge pump would generate an output voltage at the end of the chain $\mathrm{N}+1$ times higher than the supply [27] and the output voltage of such circuits can be calculated as (3) [28],

$$
V_{\text {out }}=(N+1) \cdot\left(V_{c c}-V_{T}\right)-\frac{N \cdot I_{\text {out }}}{f \cdot C}
$$

where $V_{c c}$ represents the input voltage, $V_{T}$ is the forward voltage of each diode, $N$ is the number of stages, $I_{\text {out }}$ is the charge pump output current, $f$ is the signal frequency and $C$ is the capacitance applied at each node. 
The diodes in this circuit are selected as Schottky diodes (SMS7630, Skyworks), and each coupling capacitor is 15 $\mathrm{nF}$. The minimum voltage to operate the transponder (i.e. charge pump input voltage) is $1.5 \mathrm{~V}$, the maximum diode forward bias current (i.e. charge pump output current) is 50 $\mathrm{mA}$ and the maximum forward voltage of each diode is $0.24 \mathrm{~V}$. At $13.56 \mathrm{MHz}$, the minimum output voltage of the 4-stage charge pump is calculated at $5.32 \mathrm{~V}$.

\section{Sweat Sensor Implementation and Testing}

Fig. 6(a) illustrates the charging circuit for the humidity sensor (HIH-5031, Honeywell), where V1, V2 and V3 represent the input voltage obtained from the NFC antenna, the voltage output of the Dickson charge pump which goes into a voltage regulator (LP2985-N, Texas Instruments) and the regulator output that supplies the sensor, respectively. As the NFC tag is activated by a reader, V2 and V3 are measured with an oscilloscope (Agilent DSO1014A). Fig. 6(b) presents how V2 and V3 vary with increasing tag read distance. V2 decreases in direct proportion with the read distance. As the read distance is raised from $1 \mathrm{~cm}$ to $6 \mathrm{~cm}$, $\mathrm{V} 2$ is reduced from $14.5 \mathrm{~V}$ to $5 \mathrm{~V}$ which corresponds to the calculated minimum output voltage $(5.32 \mathrm{~V})$. Meanwhile, the regulator output voltage (V3) only fluctuates slightly between $3.35 \mathrm{~V}$ and $3.38 \mathrm{~V}$, implying that as long as the reader stays within the NFC read range $(6 \mathrm{~cm}$ in our case), the sweat sensor will operate properly.

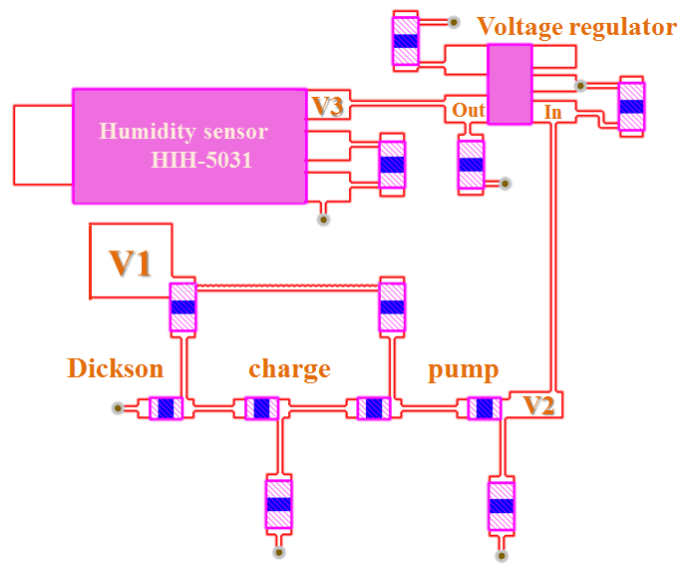

(a)

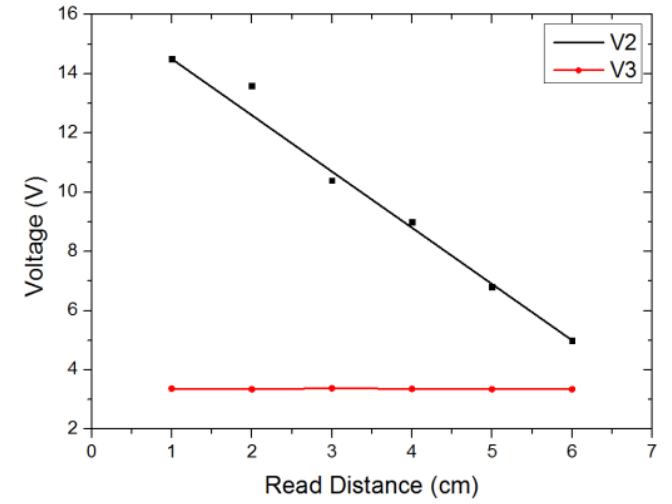

(b)

Fig. 6. (a) Sweat Sensor circuit layout and (b) V2 and V3 vs NFC read distance.
The complete smart textile NFC enabled temperature and sweat sensing device is presented in Fig. 7. The sensing circuit is fabricated on Rogers RO3006 high frequency substrate with thickness of $0.25 \mathrm{~mm}$. The ground plane of the sensing circuit is covered by a thin layer of insulating adhesive to prevent short circuits due to contact between the circuit board and the NFC antenna.

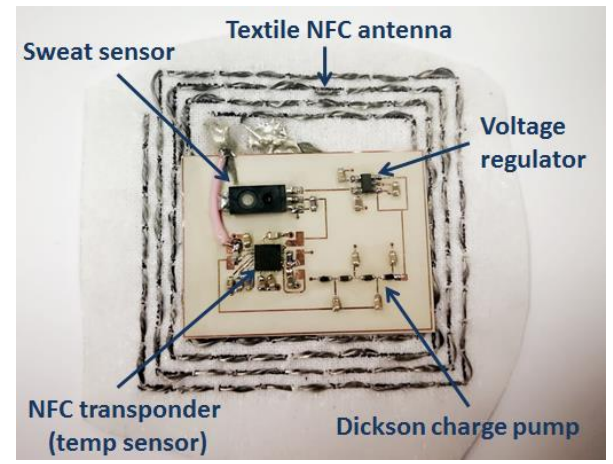

Fig. 7. Top view of the complete smart textile NFC enabled sensing system.

\section{WIRELESS SMART TEXTILE NFC ENABLED TEMPERATURE AND SWEAT SENSING SySTEM}

\section{A. Temperature Sensor}

The transponder (RF430FRL152H, Texas Instruments) has a built-in temperature sensor, and the operating range of which is $0^{\circ} \mathrm{C}-70^{\circ} \mathrm{C}$. In this work, the sensor is calibrated with two point calibration method. After calibration, the internal sensor accuracy is able to achieve $\pm 0.14^{\circ} \mathrm{C}$, which is better than most medical body thermometers on the market $\left( \pm 0.3^{\circ} \mathrm{C}\right)$ [29]. During measurements, the sensor data is collected with a TRF7970A reader and displayed on a PC.

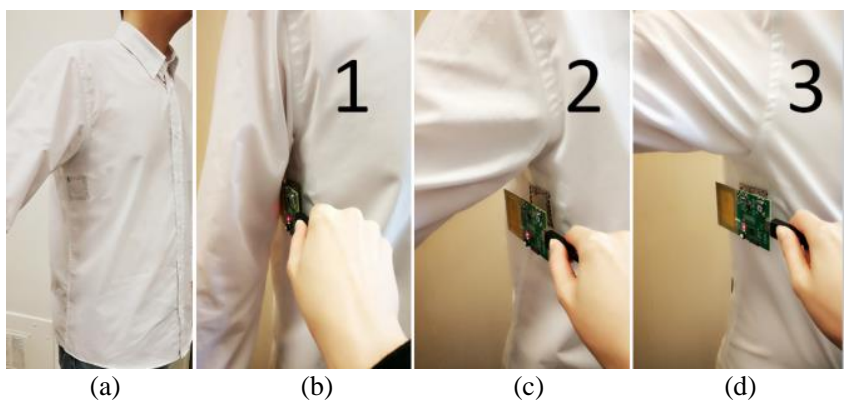

Fig. 8. (a) Overview of the smart textile NFC sensing system integrated with a shirt, and NFC sensing system read with (b) $15^{\circ}$, (c) $60^{\circ}$ and (d) $90^{\circ}$ angle between arm and body

The effect of human body towards read range has been investigated in [21], revealing that the influence of skin contact is slight enough to be neglected. As shown in Fig. 8 (a), the proposed sensing system is placed slightly below the arm pit since not only axillary temperature is one of the most accurate measurements for body temperature, but the arm pit also generates great percentage of body sweat [30]. Other than general health conditions, the proposed system is also applicable during exercise to monitor body temperature rise and increment of sweat as the oxygen intake (exercise intensity) increases [31]. The sensing 
device is positioned to make the sensors face towards human body. In this case, the sensors are protected by the cotton substrate and ensured for more accurate measurements.

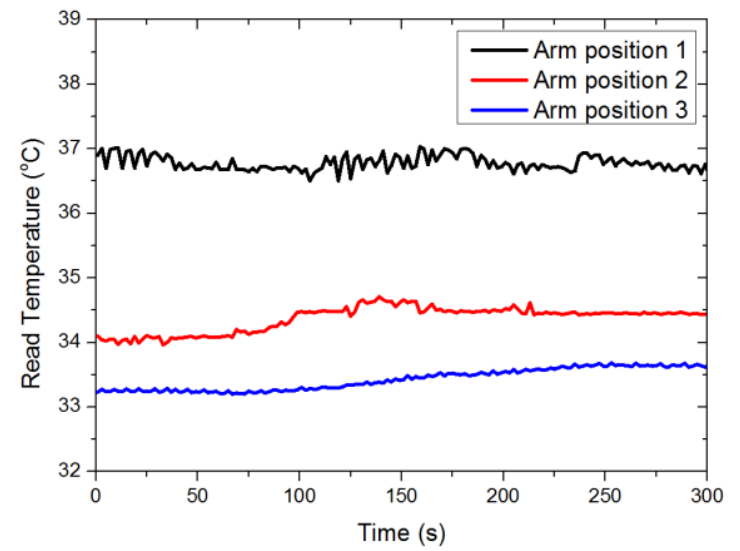

Fig. 9. Body temperature measured with three arm positions in Fig. 8 (b), (c) and (d)

In order to investigate how the temperature measurements are affected by body movements, Fig. 8(b), (c) and (d) demonstrate three different arm positions for the temperature sensor to be read (labelled as 1,2 and 3), where the arm is lifted from the body by $15^{\circ}, 60^{\circ}$ and $90^{\circ}$. The read temperature results are presented in Fig. 9, and the average measured temperature is $36.8^{\circ} \mathrm{C}, 34.4^{\circ} \mathrm{C}$ and $33.4^{\circ} \mathrm{C}$, respectively. Naturally, the closer the textile NFC sensing system stays to the body, the higher and more accurate the measured temperature is. Since the sensor is placed most closely to the body for position 1 , it tends to introduce small fluctuation to the results due to inevitable breathing action. On the other hand, the measurements from position 2 and 3 have fluctuation since there is less and less direct contact between the sensor and skin surface. However, these results are much less reliable and tend to vary with small changes of body position. In comparison, position 1 is considered the most suitable way for measurements since all the ripples shown in the test are less than $\pm 0.5^{\circ} \mathrm{C}$.

\section{B. Sweat Sensor}

The NFC transponder (RF430FRL152H, Texas Instruments) has two ADC ports, including ADC1 (reference resistor) and $\mathrm{ADC} 2$ (thermistor), mainly for determining an external thermistor value. In the resistive bias mode, a current source is sent to both reference pin and thermistor pin in order to obtain their resistance. Since the humidity sensor (HIH-5031, Honeywell) (used as sweat sensor) now connected to ADC2 operates on voltage bias, the current source is terminated for the data obtained from the transponder to completely depend on the voltage variation.

Fig. 10 shows the results of how the sweat sensor voltage output varies with detected moisture level. The change rate of humidity factor calculated from this trend is $91.3 \% / \mathrm{V}$, which is applied into the coding of the ADC input data of the NFC transponder. The real time humidity was measured wirelessly by a reader for three different conditions: room environment, normal body humidity and body after workout humidity (under the armpit area) as presented in Fig. 11.
Different from body temperature results, the humidity measurements are hardly affected by slight variation of arm positions since the humidity level around the armpit area is much more stable than temperature. The measured data indicates that for measuring environments where the humidity level is relatively steady, the sensor works smoothly in a ten-minute period with ripples less than $\pm 0.2 \%$. In the cool down process of a body workout, although the basic trend gradually drops from $77.9 \%$ to $38.1 \%$ as expected, some fluctuations still occur during this time period possibly due to slight body movements.

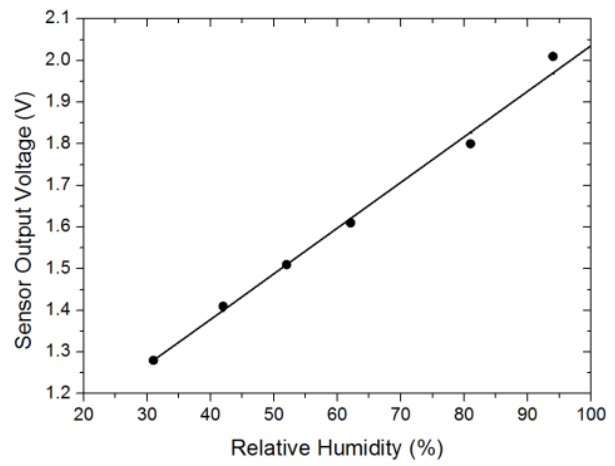

Fig. 10. Sweat sensor test results

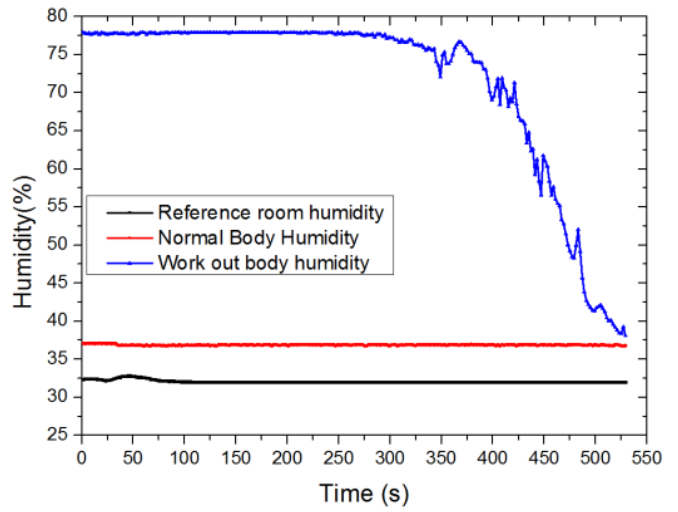

Fig. 11. Wireless measured humidity at room environment $(32.1 \%$ moisture level), normal body ( $36.9 \%$ moisture level) and body after work out $(77.9 \%$ moisture level)

\section{APPLICATIONS}

\section{A. Mobile Handset Reading}

For the sensor data to be accessed by smart phones, we have developed an Android program that reads and displays body temperature and sweat continuously from RF430FRL152H, enabling the data to be transferred into cloud storage in order to keep a record of the user's health status. As it presents in Fig. 12(a), the App uses "start" and "stop" buttons that launch and terminate the reading progress, respectively. The software interface displays four types of messages showing the tag connection status, including "Place phone on tag", "Tag connected", "Reintroducing the phone" and "Tag disconnected". It is also able to save readings by time and date.

Fig. 12(b) presents our App works on an NFC enabled Huawei Mate 7 mobile phone. The measured room temperature $\left(24.44^{\circ} \mathrm{C}\right)$ shown on screen agrees with the one measured with a Fisher Scientific thermometer $\left(24^{\circ} \mathrm{C}\right)$. 


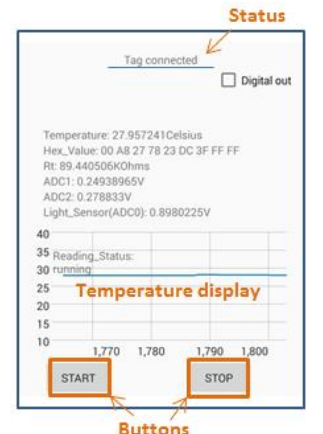

(a)

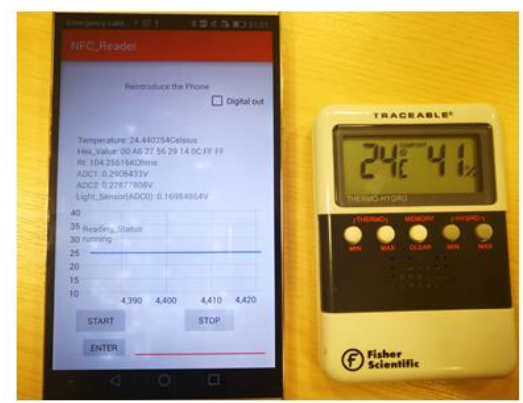

(b)
Fig. 12. NFC reader software on Android (a) Basic functions (b) Verification of the accuracy of the mobile temperature reading.

\section{B. Wound Healing Monitoring}

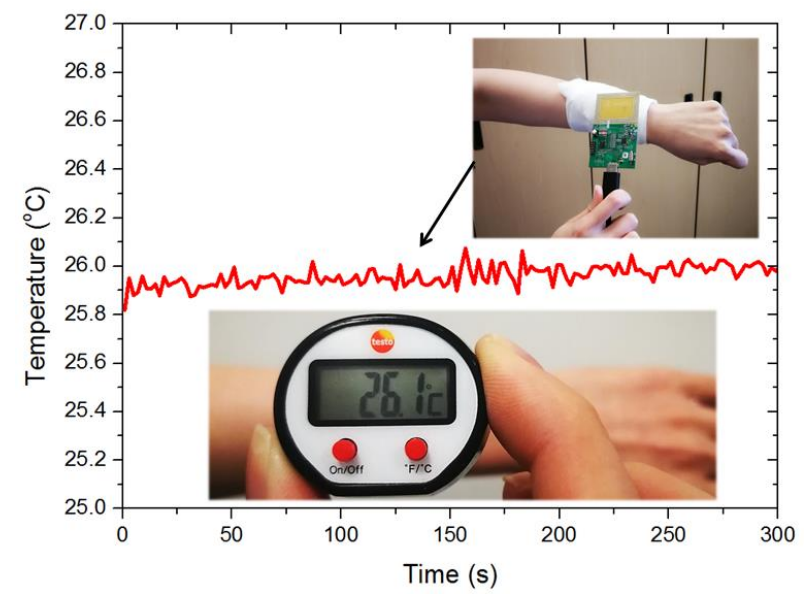

Fig. 13. Comparison between wrist ('wound') temperatures by wireless NFC sensor and Testo surface thermometer.

It has been stated in [32] and [33] that once wound tissue temperature falls below $33^{\circ} \mathrm{C}$, the activity of fibroblast and epithelial cells decreases, which might lead to a delay in the healing progress. Research about how dressing methods can affect wound healing rate has been reported [32]. However, monitoring the healing always requires multiple measurements taken before and after the clothing is changed. On the other hand, if the wound temperature goes higher than normal body temperature for certain duration, it might indicate an infection has occurred [34]. Furthermore, a high moisture environment also prevents wounds from healing [35]. For all these conditions, the proposed smart textile NFC sensing system can be a suitable tool to wirelessly detect the temperature and humidity of trauma such as wounds caused by surgical debridement and accidental injury, in order to maintain normothermia as well as prevent and detect infections.

In Fig. 13, the temperature of a 'wound' on a wrist is measured with the NFC sensing system. The proposed smart textile NFC enabled sensing device is embedded between layers of gauze that are tightly wrapped around a wrist. The measured wrist ('wound') temperature $\left(25.96^{\circ} \mathrm{C}\right)$ is compared with the temperature measured by Testo surface thermometer for validation. As a result, the accuracy of the wrist temperature measurements is $\pm 0.14^{\circ} \mathrm{C}$

\section{CONCLUSION}

This paper has presented design, fabrication implementation and measurements of smart textile NFC antennas and a battery-free wireless NFC body temperature and sweat sensing device. The textile antenna is integrated with daily garments and the sensing system is wirelessly powered, aiming for truly ubiquitous wireless health and wellbeing monitoring. The measurement results have shown that the textile NFC antennas can still perform properly under bending up to $150^{\circ}$. Both temperature and sweat sensors powered wirelessly by the reader are able to provide accurate and reliable results. Potential real-life applications relating to this smart textile sensing device, including mobile application and wound healing monitoring, have also been proposed. It is believed that the wireless powered smart textile sensing system reported here possesses potential to be widely applied into daily health care system and wellbeing monitoring.

\section{REFERENCES}

[1] S. Schneegass and O. Amft. Smart Textiles, Springer International Publishing, 2017, pp. 49-185.

[2] Y. Yun, W. Hong, D. Kim, H. Kim, Y. Jun, and H. Lee, "E-textile gas sensors composed of molybdenum disulfide and reduced graphene oxide for high response and reliability," Sensors and Actuators B: Chemical, vol. 248, pp. 829-835, Sept. 2017.

[3] A. Abdelgawad, and K. Yelamarthi, "Internet of things (IoT) platform for structure health monitoring," Wireless Communications and Mobile Computing, vol. 2017, pp. 1-10, Jan. 2017.

[4] N. Bui and M. Zorzi, "Health care applications: A solution based on the internet of things," ISABEL, Oct. 2011, Art. no. 131.

[5] S. Coyle and Y. Wu, "Bio-sensing textiles - wearable chemical biosensors for health monitoring," IFMBE Proceeding, vol. 13, pp. $35-39,2007$.

[6] G. Medrano and L. Beckmann, "Bioimpedance spectroscopy with textile electrodes for a continuous monitoring application," IFMBE Proceedings, vol. 13, pp. 23-28, 2007.

[7] T. Linz and L. Gourmelon, "Contactless EMG sensors embroidered onto textile," IFMBE Proceeding, vol. 13, pp.29-34, 2007.

[8] J. Meyer, B. Arnrich, J. Schumm and G. Troster, "Design and modeling of a textile pressure sensor for sitting posture classification," IEEE Sensors Journal, vol. 10, no. 8, pp. 1391-1398, Aug. 2010.

[9] W. Xu, M. Huang, N. Amini, L. He and M. Sarrafzadeh, "eCushion: A textile pressure sensor array design and calibration for sitting posture analysis". IEEE Sensors Journal, vol. 13, no. 10, pp. 39263934, Oct. 2013.

[10] A. Mason, S. Wylie, O. Korostynska, L. Cordova-Lopez and A. AlShamma'a, "Flexible e-textile sensors for real-time health monitoring at microwave frequencies," International Journal on Smart Sensing and Intelligent Systems, vol. 7, no. 1, pp. 32-47, Mar. 2014.

[11] M. Parrilla, R. Cánovas, I. Jeerapan, F. Andrade and J. Wang, "A textile-based stretchable multi-Ion potentiometric sensor," Advanced Healthcare Materials, vol. 5, no. 9, pp. 996-1001, Mar. 2016.

[12] X. Yang, Z. Chen, C. Elvin, L. Janice, S. Ng, J. Teo and R. Wu, "Textile fiber optic microbend sensor used for heartbeat and respiration monitoring," IEEE Sensors Journal, vol. 15, no. 2, pp. 757-761, Feb. 2015.

[13] E. Foo, R. Pettys-Baker, S. Sullivan and L. Dunne, "Bi-metallic stitched e-textile sensors for sensing salinized liquids," Proceedings of the 2017 ACM International Symposium on Wearable Computers ISWC'17, Sept. 2017.

[14] M. Husain and R. Kennon, "Preliminary investigations into the development of textile based temperature sensor for healthcare applications," Fibers, vol. 1, no. 1, pp. 2-10, Apr. 2013. 
[15] R. Soukup, A. Hamacek, L. Mracek and J. Reboun, "Textile based temperature and humidity sensor elements for healthcare applications," IEEE 37th Int. Spring Seminar on Electronics Technology, vol. 13, no. 10, May 2014.

[16] A. Lazaro, R. Villarino and D. Girbau, "A survey of NFC sensors based on energy harvesting for IoT applications," Sensors, vol. 18, no. 11, p. 3746, Oct. 2018

[17] E. Strömmer, and J. Kaartinen, "Application of near field communication for health monitoring in daily life," Proceedings of the 28th IEEE EMBS Annual International Conference, p. 3249, Dec. 2006.

[18] S. Cecil, M. Bammer, G. Schmid, K. Lamedschwandner and A. Oberleitner, "Smart NFC-sensors for healthcare applications and further development trends," $e$ \& $i$ Elektrotechnik und Informationstechnik, vol. 130, no. 7, pp.191-200, Nov. 2013.

[19] T. Leikanger, J. Häkkinen and C. Schuss, "Interfacing external sensors with Android smartphones through near field communication," Measurement Science and Technology, vol. 28, no. 4, Feb. 2017.

[20] J. Kim, G. Salvatore, H. Araki, A. Chiarelli and Z. Xie, "Batteryfree, stretchable optoelectronic systems for wireless optical characterization of the skin," Science Advances, vol. 2, no. 8, Aug. 2016.

[21] Y. Jiang, L. Xu, K. Pan, T. Leng, Y. Li, L Danoon and Z. Hu, "eTextile embroidered wearable near-field communication RFID antennas," IET Microwaves, Antennas \& Propagation, vol. 13, no. 1, pp. 99-104, Sept. 2018.

[22] R. Del-Rio-Ruiz, and J. Lopez-Garde, "Design and performance analysis of a purely textile spiral antenna for on-body NFC applications," IEEE MTT-S International Microwave Workshop Series on Advanced Materials and Processes, Sept. 2017.

[23] D. Ogoina, "Fever, fever patterns and diseases called 'fever' - A review," Journal of Infection and Public Health, vol. 4, no. 3, pp.108-124, Aug. 2011.

[24] T. Tanzawa and T. Tanaka, "A dynamic analysis of the Dickson charge pump circuit," IEEE Journal of Solid-State Circuits, vol. 32, no. 8, pp.1231-1240, Aug. 1997.

[25] D. Waidelich, and C. Shackelford, "Characteristics of voltagemultiplying rectifiers," Proceedings of the IRE, vol. 32, no. 8, pp.470-476, Aug. 1944.

[26] J. Dickson, "On-chip high-voltage generation in MNOS integrated circuits using an improved voltage multiplier technique," IEEE Journal of Solid-State Circuits, vol. 11, no. 3, pp.374-378, Jun. 1976.

[27] D. Baderna, A. Cabrini and G. Torelli, "Efficiency comparison between doubler and dickson charge pumps," 2005 IEEE International Symposium on Circuits and Systems, pp.1891-1894, Jul. 2005.

[28] D. Jan, "Fully Integrated High-Voltage Generators with Optimized Power Efficiency," Journal of Computer and Communications, vol. 2, no. 13, pp.1-8, Aug. 2014.

[29] S. John, "The best thermometers you can buy to check for fevers," Business Insider, Feb. 13, 2018. [Online]. Available: http://uk.businessinsider.com/best-thermometer?r=US\&IR=T/\#thebest-thermometer-overall-1 [Accessed 11 Sep, 2018].

[30] T. Togawa, "Body temperature measurement," Clinical Physics and Physiological Measurements, vol. 6, no.2, pp. 83-108, Oct. 1985.

[31] C. Davies, C. Barnes and A. Sargeant, "Body temperature in exercise," Internationale Zeitschrift fur Angewandte Physiologie Einschlieulich Arbeitsphysiologie, vol. 30, no. 1, pp.10-19, Mar. 1971

[32] W. McGuiness, E. Vella and D. Harrison, "Influence of dressing changes on wound temperature," Journal of Wound Care, vol. 13, no. 9 , pp.383-385, Oct. 2004.

[33] A. Kurz, D. Sessler and R. Lenhardt, "Perioperative normothermia to reduce the incidence of surgical-wound infection and shorten hospitalization," New England Journal of Medicine, vol. 334, no. 19, pp.1209-1216, May 1996.

[34] Advanced Tissue, "6 Signs You Have an Infected Wound," Advanced Tissue, Aug. 28, 2015. [Online]. Available: https://www.advancedtissue.com/6-signs-you-have-an-infectedwound/ [Accessed 1 May, 2018].

[35] S. Thomas and B. Pharm, "The effect of the weather and other environmental factors on the performance of surgical dressings," Wounds : a Compendium of Clinical Research and Practice, vol. 24, no. 12, pp.335-338, Dec. 2012.

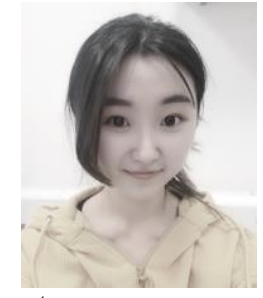

systems.

She was a translator at the annual China-Russia Technology Exposition in the summer of 2014, and she has worked as a part-time lab demonstrator at the University of Manchester, Manchester, UK, since 2016.

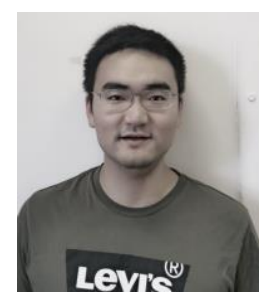

Kewen Pan was born in Jiangsu, China. He received B.Eng degree in Electrical and Electronic Engineering in 2010 from Nanjing Normal University and pursuing his $\mathrm{PhD}$ of Engineering from University of Manchester in 2015 on Graphene based Microwave Devices. His area of interest includes printed graphene antennas and 2D material based tunable microwave devices, and he has related publications in major journals and presentations in international conferences.

Ting Leng was born in Guangxi, China. He received B.Eng degree in Communication Engineering in 2010 from Coventry University and MSc. Degree in Communication Engineering in 2012 from University of Manchester, where he learned system-level software and hardware communication theories, analogue and digital communications technologies. Ting obtained his

$\mathrm{PhD}$ of Engineering from University of Manchester in 2018 on Graphene based Electronic and Sensing Devices.

$\mathrm{He}$ is currently working as research associate studying sensing properties of graphene and other 2D materials in School of Physics and Astronomy, University of Manchester. His area of interest includes screen printed graphene and graphene/2D materials sensors and electronics, and he has related publications in major journals and presentations in international conferences.

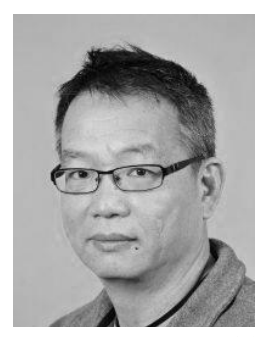

Zhirun Hu (M'98) received his B.Eng in Communication Engineering from Nanjing, China in 1982. Maser in Business Administration and $\mathrm{PhD}$ in Electrical and Electronic Engineering from the Queens' University, Belfast, UK in 1988 and 1991, respectively.

He joined the Department of Electrical and Electronic Engineering, University College of Swansea as a senior research assistant in computational semiconductor device modelling in 1991. He was with the Department of Electrical and Electronic Engineering, the Queens' University, Belfast, as a research fellow in MMIC design and characterization in 1994. In 1996, he joined GEC Marconi as a microwave technologist. He was a lecturer with the Department of Electronic Engineering, King's College London from 1998 to 2003. He is now a professor of RF and Microwave Electronics with the School of Electrical and Electronic Engineering, the University of Manchester. He has published more than 250 peer-reviewed journal and conference papers. 